\title{
DESENVOLVIMENTO RELATIVO DAS PARTES DO CORPO DE ZEBUÍNOS DE QUATRO RAÇAS
}

\author{
RELATIVE DEVELOPMENT OF BODY PORTIONS \\ FROM FOUR ZEBU BREEDS
}

\author{
André Mendes Jorge ${ }^{1}$ Carlos Augusto de Alencar Fontes ${ }^{2}$
}

\section{RESUMO}

\begin{abstract}
Utilizaram-se 63 machos não-castrados, sendo 16 de cada, das raças Gir, Guzerá, e Mocho Tabapuã e 15 da raça Nelore, com média de idade 24 meses e média de pesos vivos iniciais de 376,4; 357,6, 362,0 e 368,6kg, respectivamente. Os animais de cada raça foram divididos, aleatoriamente, em cinco categorias. Uma categoria foi abatida imediatamente $(A B)$, três receberam, em baias individuais, ração contendo $50 \%$ de concentrado na matéria seca "ad libitum" (I, II e III) e uma recebeu a mesma ração, em quantidade restrita, suprindo níveis de proteína e energia $15 \%$ acima da mantença (AR). Os animais das categorias I, II e III foram abatidos ao atingirem pesos vivos individuais de 405, 450 e 500kg, respectivamente. No abate, determinou-se o peso de corpo vazio, e pesaram-se os órgãos e vísceras. Adotou-se a equação de regressão do logaritmo da quantidade corporal de órgãos e vísceras em função do logaritmo do peso do corpo vazio. Os componentes do trato gastrintestinal e os outros órgãos internos, excetuando-se o fígado $e$ o baço, revelaram um menor ímpeto de crescimento em relação ao do peso corporal vazio.
\end{abstract}

Palavras-chave:

alometria, crescimento, órgãos, trato gastrintestinal.

\section{SUMMARY}

Sixty-three intact males, 16 Gyr, 16 Guzerat, 15 Nellore and 16 'Mocho Tabapuã', averaging, respectively, 376.4 $357.6,362.0$ and $368.6 \mathrm{~kg}$ initial live weight and twenty-four months of age, were used. The animals from each breed were divided into five groups (categories). One group was ramdomly assigned to immediate slaughter $(A B)$, three groups were full-fed a ration containing $50 \%$ concentrate, dry matter basis until reaching the slaughter weights of 405,450 and $500 \mathrm{~kg}$, respectively (group I, II and III). The fifth group was fed a restricted amount of the same ration to supply levels of protein and energy $15 \%$ above maintenance (AR). Each AR animal was slaughtered when an animal correspondent to group II reached the slaughter weight. At slaughter, the empty body weight was determined and the weight of internal organs were recorded. Regression equations of log content of internal organs, carcass and their tissues, as a function of log empty-body-weight (EBW), were fitted. The internal organs developed slower in relation to $E B W$.

Key words: allometry, gastrintestinal tract, growth, organs.

\section{INTRODUÇÃO}

Segundo BLACK (1989), existem diferenças entre genótipos quanto ao modelo de desenvolvimento ou velocidade de formação dos órgãos e dos tecidos que constituem a massa do corpo. Esta velocidade de desenvolvimento pode também ser afetada pela idade, nível nutricional e outras causas ambientais, como ficou evidenciado nos trabalhos de HENDRICKSON et al. (1965), COLEMAN et al. (1993) e PATTERSON $\boldsymbol{e}$ t al. (1994; 1995).

A proporção e a velocidade com que os tecidos se acumulam no corpo, influenciam o ganho de peso vivo e a eficiência alimentar (SHAHIN $\boldsymbol{e t}$ al., 1993). Desta forma, segundo SMITH et al. (1976), a composição do ganho poderia influir diretamente na eficiência com que os alimentos são utilizados.

\footnotetext{
${ }^{1}$ Professor Assistente, Doutor, Departamento Produção e Exploração Animal, Faculdade de Medicina Veterinária e Zootecnia, Universidade Estadual Paulista, C 560. Botucatu, SP, 18618 000, Pesquisador do CNPq. E-mail: jorgeam@ @ca.unesp.br. Autor para correspondência.

${ }^{2}$ Professor Titular, UENF, CCTA, LZNA, Campos, RJ. 
As taxas de crescimento dos órgãos e dos tecidos são afetadas direta ou indiretamente por diferentes fatores tais como tamanho do corpo adulto, nível nutricional e hormônios. A influência de fatores como temperatura ambiente, fotoperíodo, tipo racial, doenças, parasitas e exercícios sobre o tamanho de certos órgãos durante o crescimento ou à maturidade não está totalmente esclarecida (OWENS et al., 1993).

O estudo do desenvolvimento relativo dos órgãos e tecidos pode ser realizado segundo vários modelos (ROBELIN et al., 1974). HUXLEY (1924) propôs o modelo exponencial $\mathrm{Y}=\mathrm{a} . \mathrm{X}^{\mathrm{b}}$, transformado logaritmicamente em regressão linear, em que "Y" representa a fração cujo desenvolvimento se investiga, "X" é o todo que serve de referência, "a" é o valor da ordenada na origem e "b" é o coeficiente de alometria, que indica a velocidade relativa de crescimento de uma parte em relação ao todo. Quando $b=1$, o crescimento é isogônico, indicando as velocidades de desenvolvimento relativo de " $X$ " e "Y" similares no intervalo considerado. Se $b \neq 1$, o crescimento é heterogônico, indicando velocidades de desenvolvimento de " $\mathrm{X}$ " e " $Y$ " diferentes. Valor de "b" maior que 1 , alometria positiva, reflete que "Y" desenvolve-se proporcionalmente mais que "X". Quando "b" é menor que 1, alometria negativa, a intensidade de desenvolvimento de "Y" é inferior a de "X".

O coeficiente alométrico é utilizado com o intuito de se saber a relação da velocidade de crescimento de uma determinada parte frente ao todo (ROBELIN et al., 1974; OSÓRIO et al., 1994; OSÓRIO et al., 1996). Para o peso da maioria dos órgãos, em relação ao peso corporal vazio, o coeficiente alométrico, é menor que 1 , ao passo que para o total de gordura depositada aproxima-se de 2 (ROBELIN et al., 1974).

Este trabalho teve o objetivo de estudar o crescimento relativo das partes do corpo nãointegrantes da carcaça de zebuínos das raças Gir, Guzerá, Nelore e Mocho Tabapuã abatidos em diferentes estádios de maturidade.

\section{MATERIAL E MÉTODOS}

Esta pesquisa foi realizada no Laboratório de Animais do Departamento de Zootecnia da Universidade Federal de Viçosa, em Viçosa-MG. Utilizaram-se 63 bovinos machos não-castrados, sendo 16 Gir (GIR), 16 Guzerá (GUZ), 15 Nelore (NEL) e 16 Mocho Tabapuã (TAB), com média de idade de 24 meses e médias de pesos iniciais e respectivos desvios padrões de $357,6 \pm 32,95 ; 362,0$ $\pm 28,95 ; 376,4 \pm 28,56$ e $368,6 \pm 25,83 \mathrm{~kg}$, respectivamente, provenientes da Empresa de Pesquisa Agropecuária de Minas Gerais (EPAMIG). Os animais foram mantidos em regime de confinamento, distribuídos aleatoriamente em baias individuais, com área total concretada de $30 \mathrm{~m}^{2}$, sendo $8 \mathrm{~m}^{2}$ cobertos com telhas de amianto, providas de comedouro e bebedouro de concreto. Os animais de cada raça foram distribuídos em cinco grupos, cada um designado, aleatoriamente, para um do tratamentos (categorias): Abate inicial ou referência (categoria $\mathrm{AB}$ ); Alimentação restrita (categoria AR); Alimentação "ad libitum" até o abate, a um peso vivo de $405 \mathrm{~kg}$, equivalente a $90 \%$ do peso estimado à maturidade das vacas da raça (categoria I); Alimentação "ad libitum" até o abate, a um peso vivo de $450 \mathrm{~kg}$, equivalente a $100 \%$ do peso estimado à maturidade das vacas da raça (categoria II); Alimentação "ad libitum" até o abate, a um peso vivo de $500 \mathrm{~kg}$, equivalente a $110 \%$ do peso estimado à maturidade das vacas da raça (categoria III).

No tratamento $\mathrm{AB}$, foram alocados quatro animais das raças Gir, Guzerá e Mocho-Tabapuã e três da raça Nelore. Nos demais tratamentos, foram alocados três animais de cada raça. O período de adaptação teve a duração de 60 dias, fornecendo-se a todos os animais a ração utilizada no período experimental, "ad libitum". Após o período de adaptação, foram abatidos os animais do grupo $\mathrm{AB}$, servindo como referência no estudo da composição corporal inicial dos animais.

Os animais dos grupos I, II e III receberam durante o período experimental ração balanceada "ad libitum", formulada segundo as normas do NRC (1987) de modo a permitir ganho diário de $1,1 \mathrm{~kg}$, atendendo, ao mesmo tempo, às exigências de proteína degradável no rúmen (PDR) e proteína não-degradável no rúmen (PNDR), segundo o ARC (1980). Procurou-se sempre manter a proporção concentrado: volumoso (feno de capim braquiária) próxima de 1:1, na matéria seca (MS). A ração foi fornecida aos animais da categoria $\mathrm{AR}$ em quantidades limitadas, de forma a ingerirem quantidades de energia e proteína $15 \%$ acima das exigências de mantença. $\mathrm{O}$ concentrado constituiu-se de $76,5 \%$ de milho em grão triturado, $20,1 \%$ de farelo de soja, $1,6 \%$ de uréia e 1,8\% de mistura mineral. A composição química da ração é apresentada na tabela 1 .

O período experimental não teve duração pré-fixada, uma vez que os animais eram abatidos assim que atingiam os pesos préestabelecidos de 405,450 ou $500 \mathrm{~kg}$, correspondentes aos tratamentos (categorias) I, II e III, respectivamente. Para cada raça, na medida em que um animal da categoria II 
Tabela 1 - Composição química da ração experimental (\% na matéria seca).

\begin{tabular}{lr}
\hline Matéria seca & 83,78 \\
\hline Proteína bruta Energia metabolizável $^{1}$ & 12,71 \\
Cálcio & 2,42 \\
Fósforo & 0,42 \\
Magnésio & 0,22 \\
Potássio & 0,09 \\
Sódio & 0,81 \\
\hline
\end{tabular}

${ }^{1}$ Determinado em ensaio de digestibilidade; EM = ED x 0,82 (PAULINO, 1996).

atingia o peso de abate, o animal do grupo AR mais semelhante a ele quanto ao peso e condição corporal, no início do experimento, era também abatido.

Antes do período de adaptação, os animais foram pesados, após jejum de 16 horas, identificados com brincos numerados, submetidos ao controle de endo e ectoparasitas e receberam 2.000.000 UI de vitamina A injetável. Os animais foram pesados a cada 28 dias e, à medida que um animal aproximava-se do peso de abate préestabelecido, foi pesado a intervalos menores, de forma a ser abatido com o peso previsto. Antes do abate, os animais foram submetidos a um período de jejum de 16 horas, com livre acesso à água. O abate se deu após pesagem do animal, por concussão cerebral e posterior seção da veia jugular. De cada animal abatido, pesaram-se e coletaram-se amostras de sangue, rúmen-retículo, omaso, abomaso, intestino delgado, intestino grosso, mesentério, carne industrial, gordura interna, fígado, coração, rins, baço, pulmão, língua, couro, cauda, esôfago, traquéia e aparelho reprodutor. Para um animal de cada raça, foram pesados, dissecados e retiradas amostras da cabeça e de um pé. A carcaça foi dividida em duas metades, com o auxílio de uma serra elétrica, e estas pesadas individualmente.

$\mathrm{O}$ peso corporal vazio dos animais referência $(\mathrm{AB})$ foi determinado somando-se o peso da carcaça, do sangue, da cabeça, dos pés, do couro, da cauda, das vísceras e dos órgãos. Relações específicas entre o peso corporal vazio (PCVZ) e o peso vivo (PV) foram determinadas para animais de cada raça. $\mathrm{O}$ valor obtido para cada raça foi utilizado para se estimar o PCVZ inicial dos animais experimentais das categorias remanescentes (AR, I, II e III). O PCVZ final destes animais foi determinado de modo semelhante ao obtido para os animais-referência, por ocasião do abate.

No estudo do desenvolvimento relativo dos órgãos e vísceras, adotou-se a equação de regressão do logaritmo da quantidade corporal de cada órgão e cada víscera em função do logaritmo do peso do corpo vazio, conforme o modelo $Y_{i j}=\mu$ $+b_{i} X_{i j}+e_{i j}$, onde: $Y_{i j}=$ logaritmo da quantidade total de órgãos e vísceras $(\mathrm{kg})$ no corpo vazio do animal $\mathrm{j}$ da raça $\mathrm{i} ; \mu=$ efeito da média (intercepto); $b_{i}=$ coeficiente de regressão do logaritmo da quantidade de órgãos e vísceras (kg) em função do logaritmo do peso do corpo vazio, para a raça i, em que $\mathrm{i}=1$, Gir; 2, Guzerá; 3, Nelore; 4, Mocho Tabapuã; $X_{\mathrm{ij}}=$ logaritmo do peso do corpo vazio do animal $\mathrm{j}$ da raça $\mathrm{i}$; $\mathrm{e}_{\mathrm{ij}}=$ erro aleatório, pressuposto normalmente distribuído, com média zero e variância $\sigma^{2}$.

Aplicou-se o teste de identidade de modelos (GRAYBILL, 1976) para se pesquisar a existência de diferenças entre as equações referentes a várias raças.

\section{RESULTADOS E DISCUSSÃO}

O teste de identidade de modelos (GRAYBILL, 1976), aplicado às equações de regressão do logaritmo do peso de órgãos e vísceras em função do logaritmo do PCVZ, para as quatro raças estudadas (Gir, Guzerá, Nelore e Mocho Tabapuã), indicou não haver diferença $(\mathrm{P}>0,05)$ entre as raças. Deste modo, ajustaram-se equações gerais para as quatro raças, para descrever as mudanças dos pesos de órgãos (Tabelas 2 e 3) e vísceras (Tabela 4), com o aumento do PCVZ.

JORGE et al. (1999) trabalhando como os mesmos animais do presente estudo relataram não haver diferença entre raças quanto ao peso do conjunto coração+fígado+baço+pulmões (CFBP) por $100 \mathrm{~kg}$ de PCVZ, encontrando valores para o Nelore 7,7 e 8,4\% superiores aos encontrados por JORGE (1993) e PERON et al. (1993), respectivamente e $8,5 \%$ inferiores aos observados por GAZZETTA et al. (1995). Animais europeu ou mestiços de raças leiteiras tendem a apresentar maior

Tabela 2 - Parâmetros das equações de regressão do logaritmo do peso de cabeça, pés e couro $(\mathrm{kg})$ em função do logaritmo do peso corporal vazio (PCVZ), para quatro raças zebuínas (Gir, Guzerá, Nelore e Mocho Tabapuã).

\begin{tabular}{|c|c|c|c|}
\hline \multirow[t]{2}{*}{ Componentes } & \multicolumn{3}{|c|}{ Parâmetros das equações de regressão } \\
\hline & Intercepto & $\mathrm{b}$ & $r^{2}$ \\
\hline Cabeça & 0,126625 & 0,419733 & $0,30^{\text {** }}$ \\
\hline Pés & $-0,225058$ & 0,467913 & $0,45^{\text {** }}$ \\
\hline Couro & $-0,429130$ & 0,801253 & $0,71^{\text {** }}$ \\
\hline
\end{tabular}

** Significativo $(\mathrm{P}<0,01)$ 
Tabela 3 - Parâmetros das equações de regressão do logaritmo do peso de órgãos internos $(\mathrm{kg})$ em função do logaritmo do peso corporal vazio (PCVZ), para quatro raças zebuínas (Gir, Guzerá, Nelore e Mocho Tabapuã).

\begin{tabular}{lccc}
\hline \multirow{2}{*}{ Componentes } & \multicolumn{3}{c}{ Parâmetros das equações de regressão } \\
\cline { 2 - 4 } & Intercepto & $\mathrm{b}$ & $\mathrm{r}^{2}$ \\
\hline Coração & $-1,370904$ & 0,583937 & $0,39^{* *}$ \\
Fígado & $-1,865401$ & 1,004147 & $0,64^{* *}$ \\
Baço & $-2,851888$ & 1,111114 & $0,67^{* *}$ \\
Pulmões & $-1,077307$ & 0,572759 & $0,30^{* *}$ \\
\hline
\end{tabular}

*** Significativo $(\mathrm{P}<0,01)$

massa de órgãos internos, em relação ao peso vivo, que os zebuínos (PERON et al., 1993). Segundo FERREL et $\boldsymbol{a l}$. (1976), as diferenças nas exigências de energia líquida para mantença entre grupos genéticos podem ser, em parte, explicadas por diferenças no tamanho de seus órgãos internos, que são maiores nos taurinos que nos zebuínos.

Para os pesos do conjunto CFPB, baço e pulmões, por $100 \mathrm{~kg}$ de PCVZ, dos animais do presente estudo, JORGE et al. (1999) não verificaram diferenças entre a categoria $A R$ e as categorias de ganho (I, II e III). Isto, de certa forma indica que, mesmo quando os animais são submetidos à baixa restrição alimentar, por longo período de tempo, estes órgãos mantêm sua integridade, mostrando terem prioridade na utilização dos nutrientes.

Avaliando os animais do presente estudo quanto ao peso dos componentes do trato gastrintestinal (intestinos e estômagos) por $100 \mathrm{~kg}$ de

Tabela 4 - Parâmetros das equações de regressão do logaritmo dos pesos dos componentes do trato gastrintestinal $(\mathrm{kg})$ em função do logaritmo do peso corporal vazio (PCVZ), para quatro raças zebuínas (Gir, Guzerá, Nelore e Mocho Tabapuã).

\begin{tabular}{lccc}
\hline \multirow{2}{*}{ Componentes } & \multicolumn{3}{c}{ Parâmetros das equações de regressão } \\
\cline { 2 - 4 } & Intercepto & $\mathrm{b}$ & $\mathrm{r}^{2}$ \\
\hline Intestino delgado & $-1,328653$ & 0,768783 & $0,49^{* *}$ \\
Intestino grosso & $-1,028579$ & 0,589621 & $0,32^{* *}$ \\
Intestinos $^{\text {1/ }}$ & $-0,920659$ & 0,699328 & $0,51^{* *}$ \\
Rúmen-reticulo & $-0,745226$ & 0,621754 & $0,43^{* *}$ \\
Omaso & $-1,741238$ & 0,845427 & $0,31^{* *}$ \\
Abomaso & $-2,240353$ & 0,885414 & $0,51^{* *}$ \\
Estômagos $^{2 /}$ & $-0,739287$ & 0,692212 & $0,52^{* *}$ \\
TGI $^{3 /}$ & $-0,518713$ & 0,694964 & $0,57^{* *}$ \\
\hline
\end{tabular}

${ }^{* * *}$ Significativo $(\mathrm{P}<0,01)$

${ }^{1 /}$ Intestinos $=$ intestino delgado + intestino grosso

${ }^{2 /}$ Estômagos = rúmen-retículo + omaso + abomaso

${ }^{3 /}$ TGI = Intestinos + Estômagos
PCVZ, JORGE et al. (1999) não encontraram diferença entre raças. Resultados similares de peso de trato gastrintestinal (TGI) para a raça Nelore, expressos por $100 \mathrm{~kg}$ de PCVZ, foram observados por OLIVEIRA et al. (1992), JORGE (1993), OLIVEIRA et al. (1994) e GAZZETTA $\boldsymbol{e t}$ al. (1995), que encontraram, os valores de 4,4; 4,4; 5,1 e $5,7 \%$, respectivamente. Animais com sangue da raça Holandesa têm apresentado maiores pesos para o TGI que zebuínos e seus mestiços com taurinos de corte, provavelmente, em conseqüência de a seleção ser voltada principalmente para produção de leite, que exige maior consumo de alimento, especialmente no caso de altas produtoras, em relação à produção de carne.

JORGE et al. (1999) observaram nos animais do presente estudo que animais $\mathrm{AB}$ apresentaram maior peso de intestino delgado que animais AR e animais abatidos com $500 \mathrm{~kg}$ de peso vivo (categoria III), indicando que o aumento de peso desse componente do trato gastrintestinal ocorreu em ritmo mais lento que o peso corporal. $\mathrm{O}$ mesmo autor observou que animais da categoria mantença (AR) apresentaram menores pesos relativos de TGI que animais de abate inicial (AB). Isso indica que houve redução dessas vísceras quando os animais foram submetidos à restrição alimentar. Esses resultados coincidem com os de PERON et al. (1993), JORGE (1993) e OLIVEIRA et al. (1994), ao abaterem bovinos sob alimentação restrita e ad libitum.

Quanto aos pesos de rúmen-retículo (RURET), omaso e abomaso, expressos por $100 \mathrm{~kg}$ de PCVZ, dos animais do presente estudo, JORGE et al. (1999) não observaram diferença entre as categorias de ganho (I, II e III), submetidas à alimentação "ad libitum", apesar da tendência de declínio no peso dos mesmos, à medida que se elevou o peso corporal vazio.

Os coeficientes de determinação das equações de regressão $\left(r^{2}\right)$ para órgãos e vísceras, apesar de significativos $(\mathrm{P}<0,01)$, mostraram-se baixos (variando entre 0,30 e 0,57). Por outro lado, para couro, fígado e baço, os coeficientes de determinação de 0,$71 ; 0,64$ e 0,67 , respectivamente, revelaram razoável ajustamento das equações aos dados experimentais.

Os coeficientes de regressão (b) das equações das tabelas 2,3 e 4 , excetuando-se os do fígado e do baço, foram menores que 1, revelando alometria negativa, ou seja, as intensidades de desenvolvimento dessas partes do corpo foram inferiores à do peso corporal vazio. Estes resultados estão de acordo com ROBELIN et al. (1974), BLACK (1989) e OSÓRIO et al. (1994), e refletem 
a maturidade mais precoce das partes consideradas em relação ao desenvolvimento do tecido muscular e especialmente do tecido adiposo, de maturidade mais tardia.

Os coeficientes de regressão das equações para fígado $(b=1,00)$ e baço $(b=1,11)$, revelaram, respectivamente, intensidade de crescimento igual e superior à do PCVZ. Em relação à outros órgãos vitais, como por exemplo o coração $(b=0,58)$ e pulmões $(b=0,57)$, o fígado e o baço seriam de maturidade mais tardia, o que está de acordo com as observações de OSÓRIO et al. (1994).

Os coeficientes de regressão das equações para os componentes do trato gastrintestinal (entre $0,59$ e 0,88$)$ revelaram que as vísceras apresentam menor ímpeto de crescimento em relação ao do peso corporal vazio, o que confirma as observações de ROBELIN et al. (1974).

\section{CONCLUSÕES}

Os componentes do trato gastrintestinal e os outros órgãos internos de zebuínos, excetuando-se o fígado e o baço, revelam menor ímpeto de crescimento em relação ao do peso corporal vazio.

\section{REFERÊNCIAS BIBLIOGRÁFICAS}

AGRICULTURAL RESEARCH COUNCIL - ARC. The nutrient requirements of ruminants livestock. London: Commonwealth Agricultural Bureaux, 1980. 351p.

BLACK, L.L. Crecimiento y desarrollo de corderos. In: HARESIGN, W. Producción ovina. México : AGT, 1989. p. $23-62$

COLEMAN, S.W., EVANS, B.C., GUENTHER, J.J. Body and carcass composition of angus and charolais steers as affected by age and nutrition. J Anim Sci, v.71, p.86-95, 1993.

FERRELL, C.L.; GARRETT, W.N.; HINMAN, N., et al. Energy utilization by pregnant heifers. J Anim Sci, v.42, n.4, p.937950, 1976.

GAZZETTA, M.C.R.R.; ITURRINO, R.P.S.; CAMPOS, B.E.S et al. Avaliação corporal de búfalos (Bubalus bubalis) e bovinos nelore (Bos indicus), terminados em confinamento. Bol Ind Anim, v.52, n.1, p.77-86, 1995.

GRAYBILL, F.A. Theory and aplication of the linear model. Massachussetts : Duxburg Press, 1976. 704p.

HENDRICKSON, R.L., POPE, L.S., HENDRICKSON, R.F. Effect of rate gain of fattening beef calves on carcass composition. $\mathbf{J}$ Anim Sci, Champaign, v.24, p.507-517, 1965.

HUXLEY, J.S. Constant differential growth ratios and their significance. Nature, London, v.114, p.895-896, 1924.

JORGE, A.M. Ganho de peso, conversão alimentar e características da carcaça de bovinos e bubalinos. Viçosa, 1993. N.p. Dissertação (Mestrado em Zootecnia) - Curso de Pós-graduação em Zootecnia, Universidade Federal de Viçosa, 1993.
JORGE, A.M., FONTES, C.A.A., PAULINO, M.F., $\boldsymbol{e t}$ al. Tamanho relativo dos órgãos internos de zebuínos sob alimentação restrita e ad libitum. Rev Bras Zootec, v.28, n.2, p.374-380, 1999.

NATIONAL RESEARCH COUNCIL - NRC. Predicting feed intake of food producing animal. Washingtong, D.C. National Academic, 1987. 92p.

OLIVEIRA, R.F.M., FONTES, C.A.A., CARNEIRO, L.H.D., et al. Biometria do trato gastrintestinal de bovinos de três grupos genéticos. R Soc Bras Zootec, v.21, n.2, p.205-210, 1992.

OLIVEIRA, M.A.T. de, FONTES, C.A.A., LANA, R. de P., $\boldsymbol{e}$ t al. Biometria do trato gastrintestinal e área corporal de bovinos. R Soc Bras Zootec, v.23, n.4, p.576-584, 1994.

OSORIO, J.C. da S., JARDIM, P.O. da C., SIEWERDT, F., et al. Desenvolvimento relativo dos cortes do serrote em bovinos holandês. R Soc Bras Zootec, v.25, n.3, p.449-457, 1996.

OSORIO, J.C. da S., SIEWERDT, F., OSÓRIO, M.T.M. et al. Desenvolvimento alométrico das regiões corporais em ovinos. In: REUNIÃO ANUAL DA SOCIEDADE BRASILEIRA DE ZOOTECNIA, 31, 1994, Maringá. Anais... Maringá: SBZ, 1994. p. 240 .

OWENS, F.N., DUBESKI, P., HANSON, C.F. Factors that alter the growth and development of ruminants. J Anim Sci, Champaign, v.71, n.11, p.3138-50, nov. 1993.

PATTERSON, D.C., MOORE, C.A., STEEN, R.W. The effects of plane of nutrition and slaughter weight on the performance and carcass composition of continental beef bulls given high forage diets. Anim Prod, Cambrigde, v.58, n.1, p.41-47, 1994

PATTERSON, D.C., STEEN, R.W., KILPATRICK, D.J. Growth and development in beef cattle. 1. Direct and residual effect of plane of nutrition during early life on components of gain and food efficiency. J Agric Sci, Cambrigde, v.124, n.1, p.91-100, 1995.

PAULINO, M.F. Composição corporal e exigências de energia, proteína e macroelementos minerais $(\mathrm{Ca}, \mathrm{P}, \mathrm{Mg}, \mathrm{Na}$ e $\mathrm{K}$ ) de bovinos não-castrados de quatro raças zebuínas em confinamento. Viçosa, 1996. 80p. Tese (Doutorado em Zootecnia) - Curso de Pós-graduação em Zootecnia, Universidade Federal de Viçosa, 1996.

PERON, A.J., FONTES, C.A.A., LANA, R.P., et al. Tamanho de órgãos internos e distribuição da gordura corporal, em novilhos de cinco grupos genéticos, submetidos a alimentação restrita e 'ad libitum". R Soc Bras Zootec, v.22, n.5, p.813$819,1993$.

ROBELIN, J., GEAY, Y., BÉRANGER, C. Croissance relative des différentes tissus, organes at régions corporelles des taurillons frisons, durant la phase d'engraissement de 9 a 15 mois. Ann Zootech, Paris, v.23, p.313-323, 1974.

SHAHIN, K.A., BERG, R.T., PRICE, M.A. The effect of breedtype and castration on tissue growth patterns and carcass composition in cattle. Livest Prod Sci, Amsterdam, v.35, n.3/4, p.251-64, jun. 1993.

SMITH, G.M., LASTER, D.B., CUNDIFFF, L.V. et al. Characterization of biological types of cattle. II. Postweaning growth and feed efficiency of steers. J Anim Sc, Champaign, v.43, n.1, p.37-47, jul. 1976. 